\title{
Modifications of Au Nanoparticle-Functionalized Graphene for Sensitive Detection of Sulfanilamide
}

\author{
Bao-Shan $\mathrm{He}$ * (D) and Xiao-Hai Yan \\ School of Food Science and Technology, Henan Key Laboratory of Cereal and Oil Food Safety Inspection \\ and Control, Henan University of Technology, Zhengzhou 450001, China; taotao5510@126.com \\ * Correspondence: baoshanhe2008@haut.edu.cn; Tel.: +86-371-6775-8022
}

Received: 6 February 2018; Accepted: 10 March 2018; Published: 13 March 2018

\begin{abstract}
In this paper, we present a simple and feasible electrochemical sensor based on $\mathrm{Au}$ nanoparticle-functionalized graphene for the determination of sulfanilamide. Au nanoparticles were deposited on graphene, which acted as a platform to prepare excellent nanocomposites. Attributed to the graphene's large surface area and the Au nanoparticles' strong conductivity, many sulfanilamide molecules were enriched on the sensor surface and the signal response became more sensitive. Under the optimal conditions, the electrochemical sensors could be used for the efficient detection of sulfanilamide. Good linearity was observed in the range of $0.1-1000 \mu \mathrm{mol} \cdot \mathrm{L}^{-1}$ and the detection limit was $0.011 \mu \mathrm{mol} \cdot \mathrm{L}^{-1}$. Most importantly, the Au nanoparticle-functionalized graphene-modified electrode could be successfully applied for the detection of sulfanilamide in animal meat, and exhibited good stability, acceptable recovery, and offered a promising platform for point-of-care detecting in real samples.
\end{abstract}

Keywords: electrochemical sensor; Au nanoparticles; graphene; sulfanilamide

\section{Introduction}

Sulfonamides (SAs) are one of the oldest classes of antibiotic drugs with widespread applications in prophylactic, therapeutic, and growth promoting [1,2] treatments, thanks to their low toxicity and high efficiency against bacterial diseases [3-6]. Recently, however, due to the abuse of SAs, their residues have become a considerable concern. It has reported that long-term use can produce certain side effects, such as emiction [6], hemopoiesis turbulence [6,7], allergic hypersensitivity reactions in humans, and carcinogen resulting in hypothyroid [8]. In response to the dangers of SAs, the maximum residue level (MRL) of SAs was established as $100 \mu \mathrm{g} / \mathrm{kg}$ [9] in the European Union.

To date, microbiological methods [10], immunoassays [11,12], spectrophotometry [13], chromatography $[14,15]$, and liquid chromatography tandem mass spectrometry (LC-MS/MS) [16-18] are widely used in the detection of SAs. All of these methods are restricted with costly instruments, complicated operation processes, and time-consuming detection processes. However, electrochemical methods $[19,20]$ have seen rapid development owing to their superior sensitivity, high accuracy, and suitability for point-of-care testing. For example, $\mathrm{Fe}_{3} \mathrm{O}_{4} / \mathrm{Gr} / \mathrm{GCE}$ electrochemical sensors [19] and MIPs/QDs@SiO 2 fluorescence sensors [21] have been reported for the detection of sulfanilamide. Obviously, electrochemical sensors have a lower detection limit. Hence, it is necessary to develop electrochemical methods for the detection of sulfanilamide.

Graphene (Gr), with a one-atom-thick honeycomb structure, has been widely used in many fields owing to its outstanding properties such as high surface area, low cost, good stability, good conductivity, and biocompatibility [22-25]. Thanks to its large surface and distinctive structure, $\mathrm{Gr}$ can be made into excellent nanocomposites in combination with a wide variety of nanomaterials. Au nanoparticles (AuNPs) are famous for their superior properties, such as ease of functionalization and synthesis, 
chemical stability, and good biocompatibility and conductivity [26,27]. Because of these unique properties, AuNPs can be easily utilized as an excellent functionalized material.

In this work, a simple, feasible, and convenient electrochemical sensor for detecting sulfanilamide based on AuNP-functionalized Gr was constructed. Gr provided a large platform and the introduction of AuNPs raised its stability and maintained its inherent performances, for example, its large surface area and excellent conductivity. The AuNPs/Gr promoted electron transfer in the electropolymerization oxidation of sulfanilamide as electron transfer mediators when analytes were enriched on the surface of the electrode (Scheme 1). According to the changes of the differential pulse voltammetry response current, the detection of sulfanilamide could be achieved.

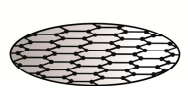

Gr

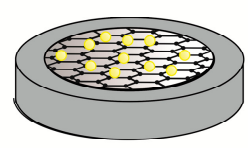

AuNPs/Gr GCE
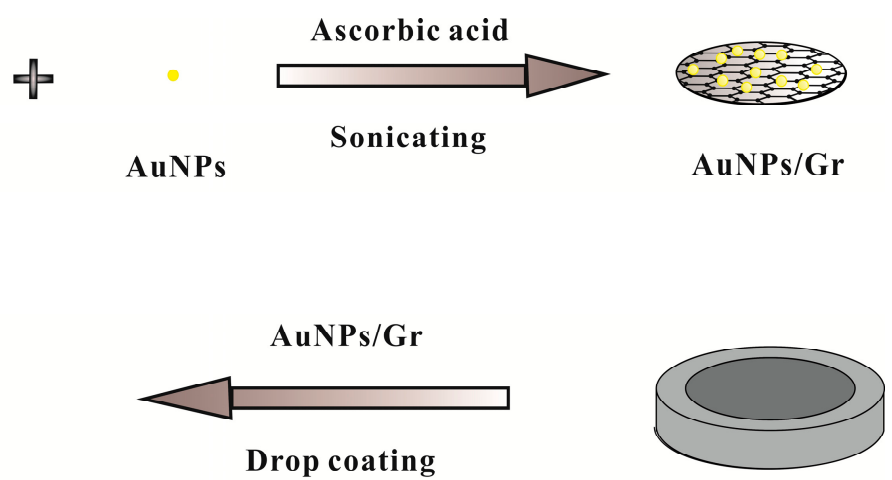

Bare GCE

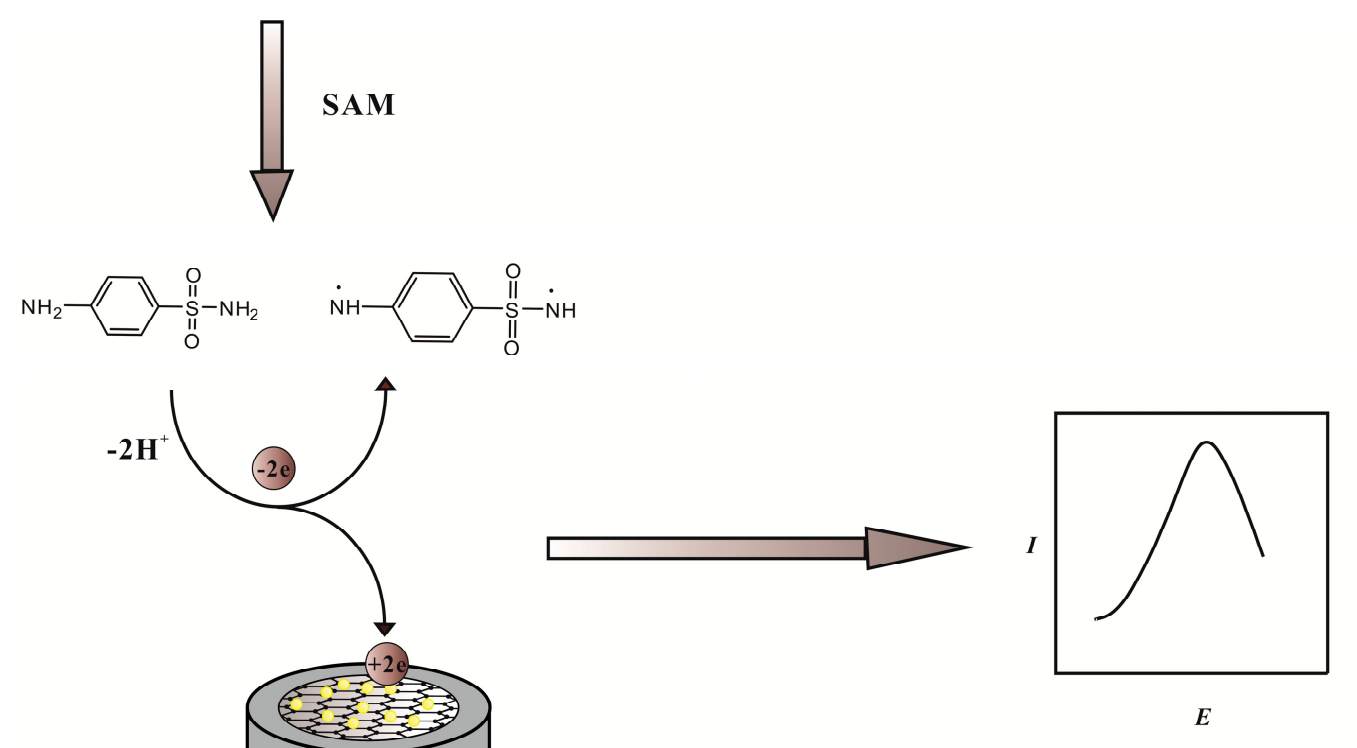

The surface of the electrode

Scheme 1. Schematic diagram of the sulfanilamide sensor.

\section{Experimental}

\subsection{Materials and Reagents}

All chemicals were of at least analytical grade and were used without further purification. Gr was purchased from Ningbo Institute of Industrial Technology. N,N-Dimethyl formamide (DMF), Sulfanilamide (SAM), and Ascorbic Acid were obtained from Tianjin Kemiou Chemical Reagent Co., Ltd. (Tianjin, China). Chloroauric Acid $\left(\mathrm{HAuCl}_{4}\right)$ was provided by Shanghai Aladdin Biochemical Technology Co., Ltd. (Shanghai, China). Potassium ferricyanide $\left(\mathrm{K}_{3}\left[\mathrm{Fe}(\mathrm{CN})_{6}\right]\right)$, potassium ferrocyanide 
$\left(\mathrm{K}_{4}\left[\mathrm{Fe}(\mathrm{CN})_{6}\right]\right)$, and reagents for preparing Britton-Robinson (BR) buffer solution $\left(\mathrm{HBO}_{3}, \mathrm{H}_{3} \mathrm{PO}_{4}, \mathrm{H}_{2} \mathrm{SO}_{4}\right.$, $\mathrm{HNO}_{3}$ ) were purchased from Luoyang Chemical Reagent Factory (Luoyang, China). AuNPs/Gr nanocomposites were dissolved in DMF. SAM solutions were prepared in $0.04 \mathrm{~mol} \cdot \mathrm{L}^{-1}$ Britton-Robinson (BR) buffer solution. Any other solvent used was double distilled water, if not clearly indicated otherwise.

\subsection{Instruments}

The morphology of materials was investigated via transmission electron microscopy (TEM) on an HT7700 (Hitachi, Japan) and energy dispersive X-ray (EDX) spectroscopy. Ultraviolet spectrophotometer (UV-vis) absorption spectra were recorded using a UV-6100s Double beam spectrophotometer (Mapada, Shanghai, China). Differential pulse voltammetry (DPV), cyclic voltammetry (CV), and electrochemical impedance spectroscopy (EIS) measurements were carried out using a CHI660E electrochemical workstation (Shanghai Chen Hua Instrument Co., Ltd., Shanghai, China).

\subsection{Synthesis of $A u N P s / G r$ Nanocomposites}

AuNPs/Gr nanocomposites were prepared according to a previously reported method [28]. At room temperature, $800 \mu \mathrm{L}$ of $5 \mathrm{mmol} \cdot \mathrm{L}^{-1}$ chloroauric acid solution was added to a glass beaker containing $400 \mu \mathrm{L}$ of $1.0 \mathrm{~g} \cdot \mathrm{L}^{-1} \mathrm{Gr}$. The mixture was mixed evenly after the addition of $7.8 \mathrm{~mL}$ double distilled water and the homogeneous suspension was formed by sonication for $5 \mathrm{~min}$. Meanwhile, $1 \mathrm{~mL}$ ascorbic acid solution $\left(0.1 \mathrm{~mol} \cdot \mathrm{L}^{-1}\right)$ was slowly added to the abovementioned glass beaker and kept for 2 days after $40 \mathrm{~min}$ of treatment. Centrifugation and washing were executed to remove most of the matrices, including ascorbic acid. Lastly, products were collected for further use after drying.

\subsection{Fabrication of the $A u N P s / G r / G C E$}

A conventional three-electrode cell was used containing a platinum wire as a counter electrode, $\mathrm{Ag} / \mathrm{AgCl}$ (saturated $\mathrm{KCl}$ ) as the reference electrode, and a modified glassy carbon electrode (GCE, $\Phi=3 \mathrm{~mm}$ ) as the working electrode. The bare GCE was firstly polished with $0.05 \mathrm{~mm}$ alumina powder, followed by successive sonication in (1:1) $\mathrm{HNO}_{3}$, ethanol, and water to obtain a cleaned GCE surface. The cleaned GCE was activated by $\mathrm{CV}$ scanning in a $0.5 \mathrm{~mol} \cdot \mathrm{L}^{-1} \mathrm{H}_{2} \mathrm{SO}_{4}$ solution before use. AuNPs/Gr $\left(1.0 \mathrm{~g} \cdot \mathrm{L}^{-1}\right)$ suspensions were prepared by ultrasonically dispersing $1 \mathrm{mg}$ AuNPs/Gr nanocomposites in $1 \mathrm{~mL}$ DMF. Then, $2 \mu \mathrm{L}$ as-prepared AuNPs/Gr $\left(1.0 \mathrm{~g} \cdot \mathrm{L}^{-1}\right)$ suspensions were dropped onto cleaned GCE and dried for measuring CV and EIS, which were conducted in $5 \mathrm{mM}$ $\left[\mathrm{Fe}(\mathrm{CN})_{6}\right]^{3-}$ solution containing $0.10 \mathrm{~mol} \cdot \mathrm{L}^{-1} \mathrm{KCl}$ and $10 \mathrm{mM}\left[\mathrm{Fe}(\mathrm{CN})_{6}\right]^{3-/ 4-}$ solution containing $0.10 \mathrm{~mol} \cdot \mathrm{L}^{-1} \mathrm{KCl}$ as a redox probe, respectively [29]. The preparation of $\mathrm{Gr} / \mathrm{GCE}$ was the same as the abovementioned process. All of the experiments were carried out at room temperature.

\section{Results and Discussion}

\subsection{Characterization of $A u N P s / G r$}

Transmission electron microscopy (TEM) images of AuNPs/Gr in Figure 1 were used to support the successful attachment of AuNPs onto Gr. As illustrated in Figure 1a, the Gr exhibited a thin, flaky, and folding structure that demonstrated a large surface area. Figure $1 \mathrm{~b}$ shows that a number of small black particles were evenly dispersed on the Gr surface, showing the successful preparation of the AuNPs/Gr nanocomposites. The UV-vis spectra of Gr and AuNPs/Gr were recorded. As shown in Figure 2a, no absorption peak was observed for pure Gr. After AuNPs were mixed with Gr, Figure $2 \mathrm{~b}$ shows an obvious absorption peak at approximately $550 \mathrm{~nm}$ wavelength, like that of pure AuNPs. Both UV-vis spectra and TEM demonstrated that AuNPs/Gr nanocomposites were constructed successfully. All of the abovementioned results were consistent with the previous literature [30]. 


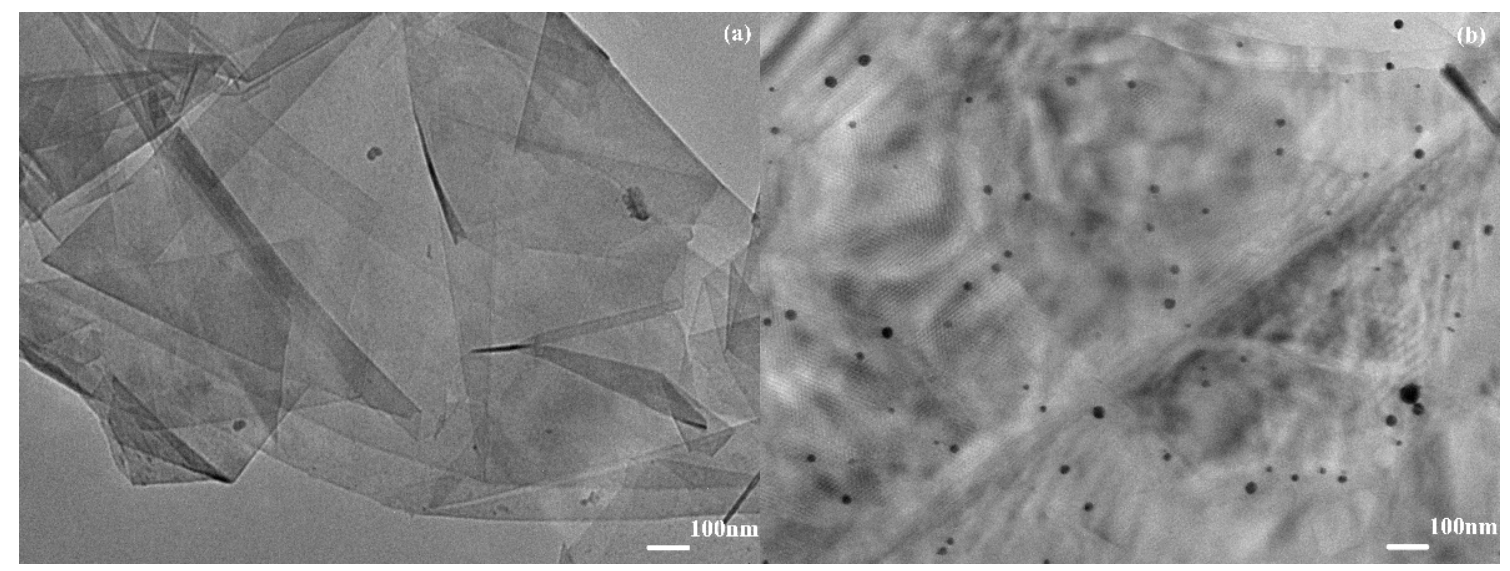

Figure 1. TEM images of Gr (a) and Au nanoparticles (AuNPs)/Gr (b).

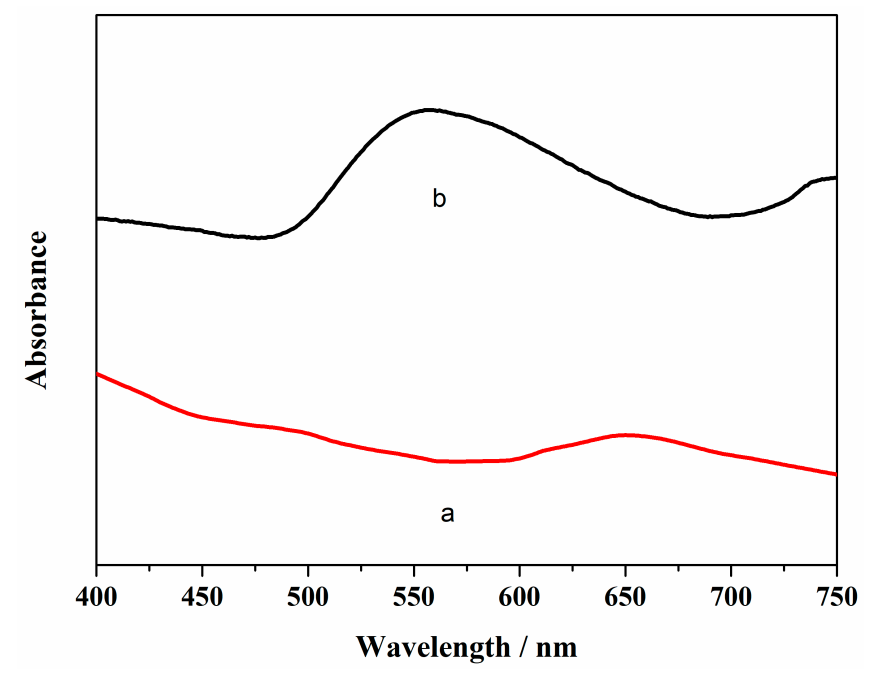

Figure 2. UV-vis absorption spectra of (a) Gr and (b) AuNPs/Gr.

To further verify the successful synthesis of AuNPs/Gr nanocomposites, the EDX spectrum of AuNPs/Gr nanocomposites was measured to determine elemental compositions. In Figure 3, the peaks corresponding to $\mathrm{Au}$ and $\mathrm{C}$ elements are clearly observed, indicating the presence of AuNPs and $\mathrm{Gr}$ and the validity of the above conclusion.

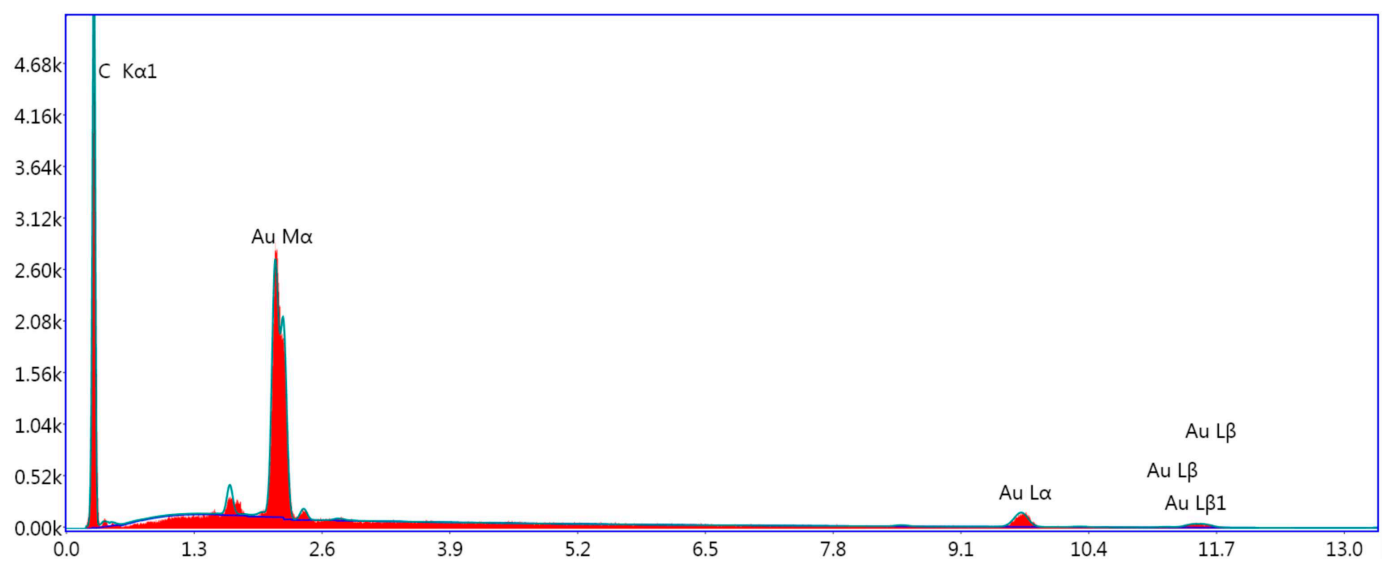

Figure 3. Energy dispersive X-ray EDX spectrum of the AuNPs/Gr nanocomposites. 


\subsection{Surface Morphology of the Modified Electrodes}

The characterization of the electron transfer properties of the different modified electrodes is always carried out using EIS, which is measured in $\left[\mathrm{Fe}(\mathrm{CN})_{6}\right]^{3-/ 4-}$ solution [31]. Ferrocyanide/ferricyanide act as strong redox probes, which are used to judge if the electrode surface modified successfully by whether the electron transfer resistance (Rct) changed as expected. The larger the Rct is, the larger the Nyquist diagram semicircular diameter is. Figure 4 shows the Rct of the GCE, Gr/GCE, and AuNPs/Gr/GCE, respectively. The Rcts were obtained using the equivalent circuit (the inset of Figure 3). The bare GCE exhibited relatively good conductivity and the Rct was approximately $243.5 \Omega$ (curve a). Upon the modification of Gr, the Rct became $75.13 \Omega$ (curve b) and the diameter was obviously decreased, which was attributed to the superior conductivity of Gr which thus increased the electron transfer rate. After modifying AuNPs/Gr, the diameter of the semicircle was further decreased and the Rct was approximately $25.42 \Omega$ (curve c), implying that the combination of Gr and AuNPs provided stronger conductivity, a larger electrochemically active surface area, and made more electrons reach the surface of the GCE.

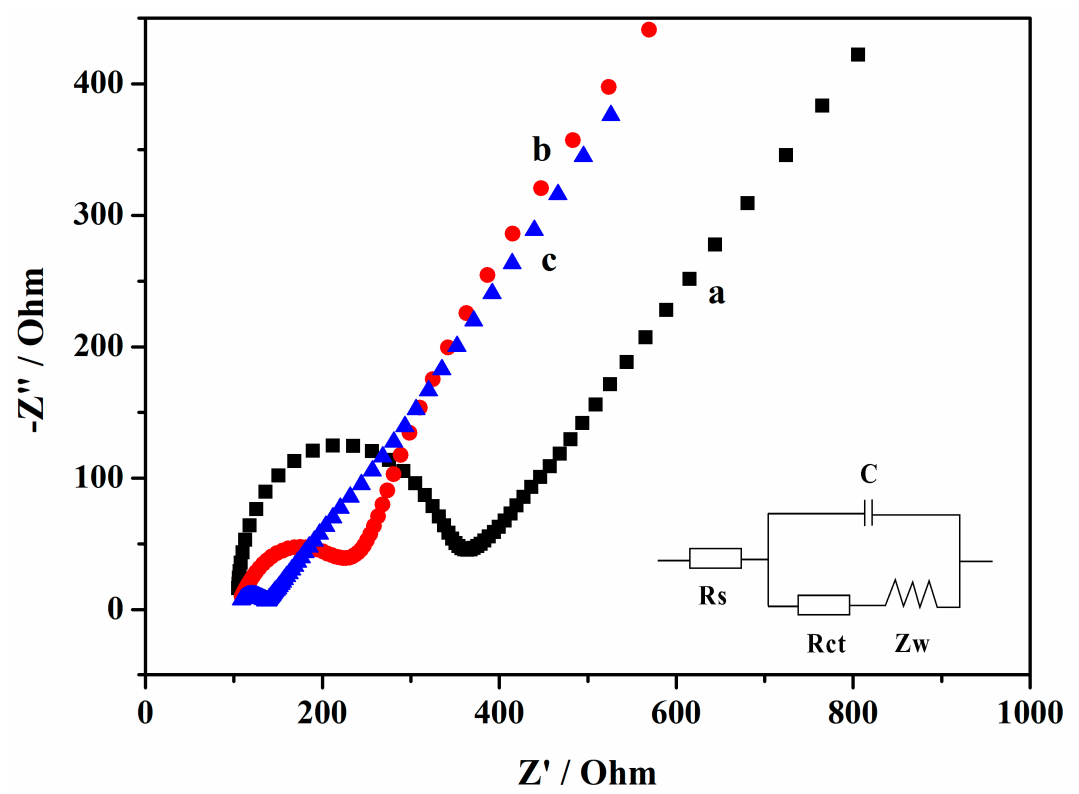

Figure 4. Electrochemical impedance spectroscopy (EIS) measurements of different modified glassy carbon electrodes (GCEs) in $0.10 \mathrm{~mol} \cdot \mathrm{L}^{-1} \mathrm{KCl}$ aqueous solution containing $10 \mathrm{mM}\left[\mathrm{Fe}(\mathrm{CN})_{6}\right]^{3-/ 4-}$ :

(a) bare GCE; (b) Gr/GCE; (c) AuNPs/Gr/GCE. The inset is the equivalent electric circuit of impedance.

\subsection{Electrochemical Response of $S A M$ on $A u N P s / G r / G C E$}

As shown in Figure 5, no oxidation peak was observed when using the GCE to scan in the absence of SAM (curve a). Also in Figure 5, the bare GCE showed a significant oxidation peak in the presence of SAM and the oxidation peak current value was $23.19 \mu \mathrm{A}$ at about $1.064 \mathrm{~V}$ (curve b). The oxidation peak current value of Gr/GCE increased slightly to $25.22 \mu \mathrm{A}$ and the electric potential was about $1.076 \mathrm{~V}$ (curve c). Compared with the Gr/GCE, the oxidation peak current value of AuNPs/Gr/GCE increased significantly to $35.71 \mu \mathrm{A}$ at about $1.115 \mathrm{~V}$ (curve d). Figure 5 indicates that unmodified and modified electrodes generated an obvious signal response in the presence of SAM (curves b, c, and d to curve a). The modification of Gr increased the activity area and conductivity of the electrode (curve $c$ to curve $b$ ). The significant increase of the oxidation peak (curve $d$ to curve $c$ ) indicated that the introduction of AuNPs further enhanced conductivity. 


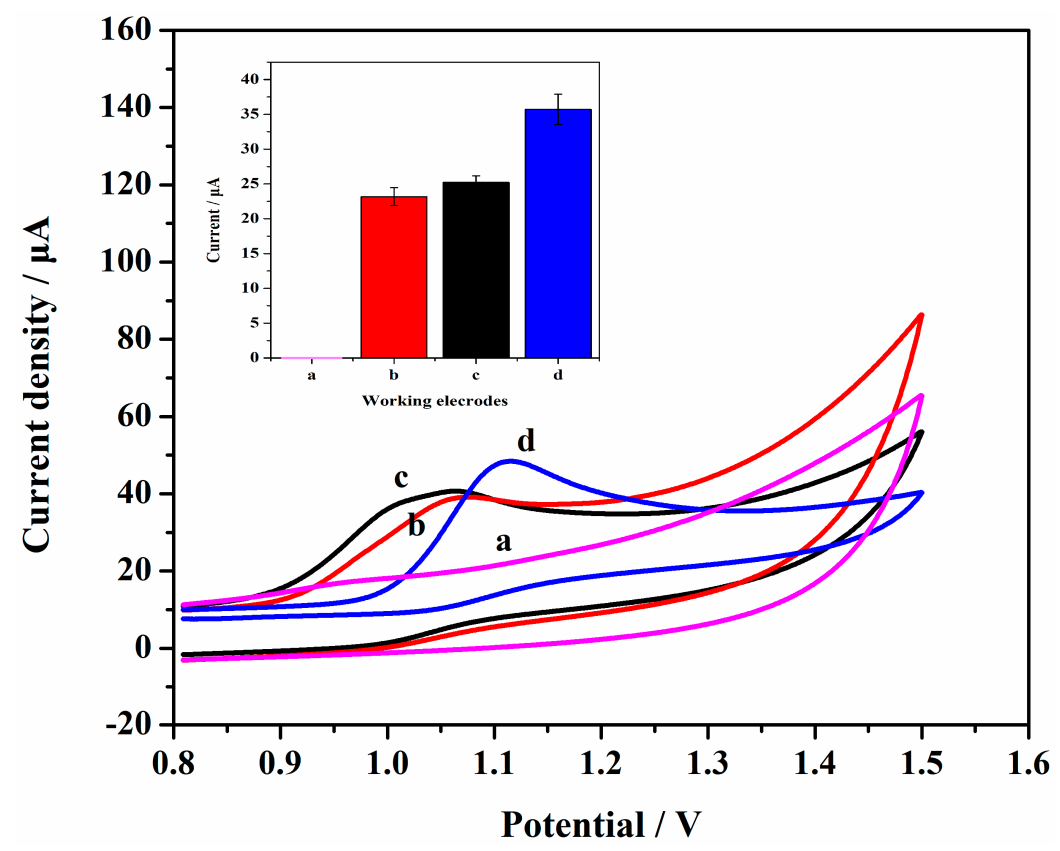

Figure 5. Cyclic voltammetry (CV) curves of (a) bare GCE without Sulfanilamide (SAM); (b) bare GCE; (c) Gr/GCE; and (d) AuNPs/Gr/GCE in $1.0 \times 10^{-3} \mathrm{~mol} \cdot \mathrm{L}^{-1} \mathrm{SAM}(\mathrm{pH}=2.0)$. The inset is the quantification of peaks appearing on the voltammogram. The potential sweep rate was $100 \mathrm{mV} \cdot \mathrm{s}^{-1}$.

\subsection{Effects of Different Scanning Rates}

Figure 6a shows the CVs of different scan rates in the determination of $1.0 \times 10^{-3} \mathrm{~mol} \cdot \mathrm{L}^{-1}$ SAM at the surface of AuNPs/Gr/GCE. As shown in Figure 6b, the logarithm of oxidation peak current value increased linearly as the logarithm of scan rates increased, and the linear regression equation was: $\operatorname{Lg} I(\mathrm{~A})=-3.914+0.772 \mathrm{Lg} v\left(\mathrm{~V} \cdot \mathrm{s}^{-1}\right)\left(\mathrm{R}^{2}=0.970\right)$. The slope was 0.772 , illustrating an adsorption-controlled process of SAM on AuNPs/Gr/GCE. Therefore, in order to prevent excessive charging current and obtain a better peak shape, we chose a scanning rate of $100 \mathrm{mV} \cdot \mathrm{s}^{-1}$.

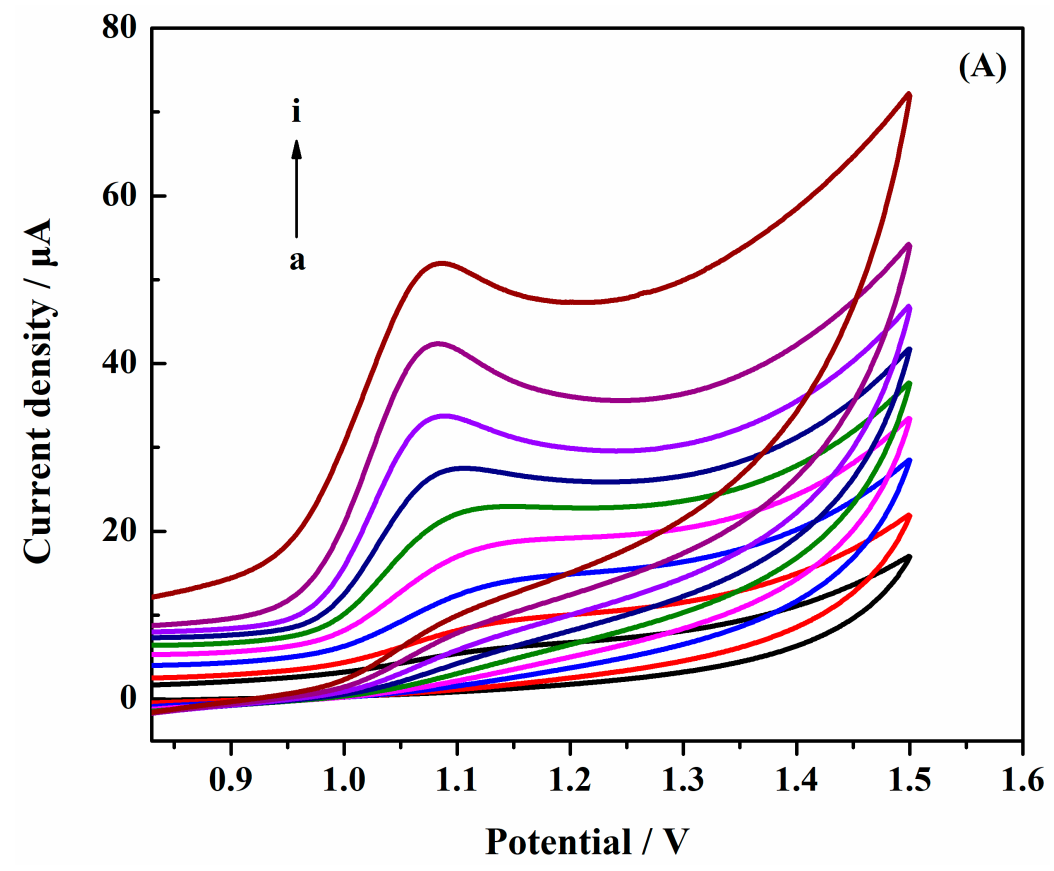

Figure 6. Cont. 


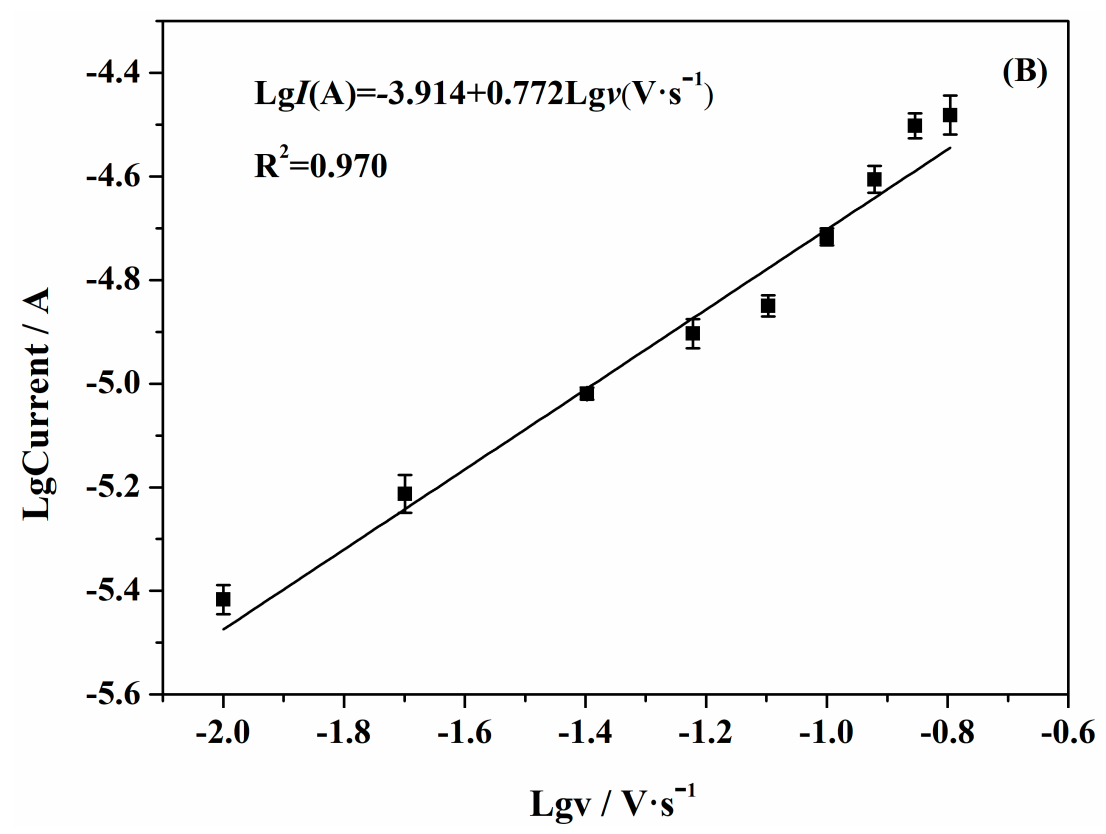

Figure 6. (A) CVs of AuNPs/Gr/GCE at different scan rates: (a) 10; (b) 20; (c) 40; (d) 60; (e) 80; (f) 100; (g) 120; (h) 140; (i) $160 \mathrm{mV} \cdot \mathrm{s}^{-1}$; (B) Relationship of the logarithm of oxidation peak current versus the logarithm of scan rates.

\subsection{Influence of $p H$}

The effects of $\mathrm{pH}$ on the performance of AuNPs/Gr/GCE were studied systematically. Figure 7a depicts the $\mathrm{CV}$ curves at different $\mathrm{pHs}$. The potential was shifted to less values with increasing $\mathrm{pH}$, which may be due to the effect of protons. Figure $7 \mathrm{~b}$ illustrates the relationship diagram of the oxidation peak current versus $\mathrm{pHs}$, and it was easy to find that the highest value of $\mathrm{pH}$ was 2.0. As the $\mathrm{pH}$ value became larger or smaller, other oxidation peak current values decreased. It could thus be concluded that the optimal $\mathrm{pH}$ value was 2.0.

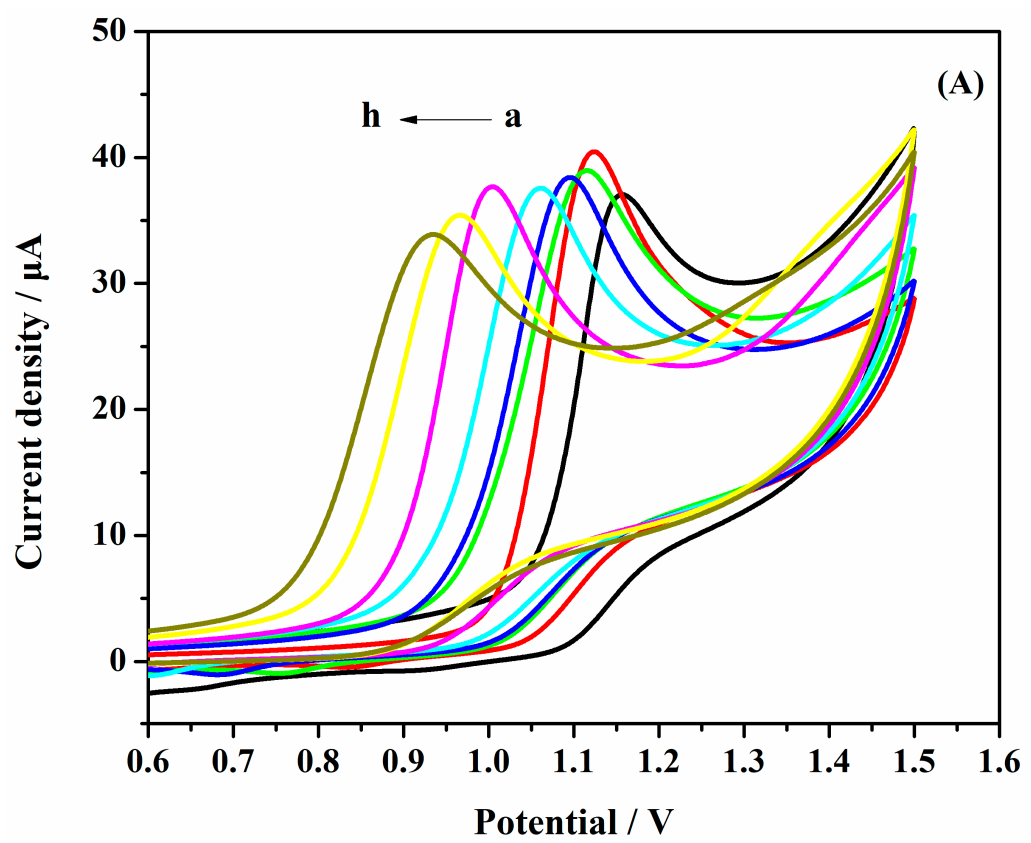

Figure 7. Cont. 


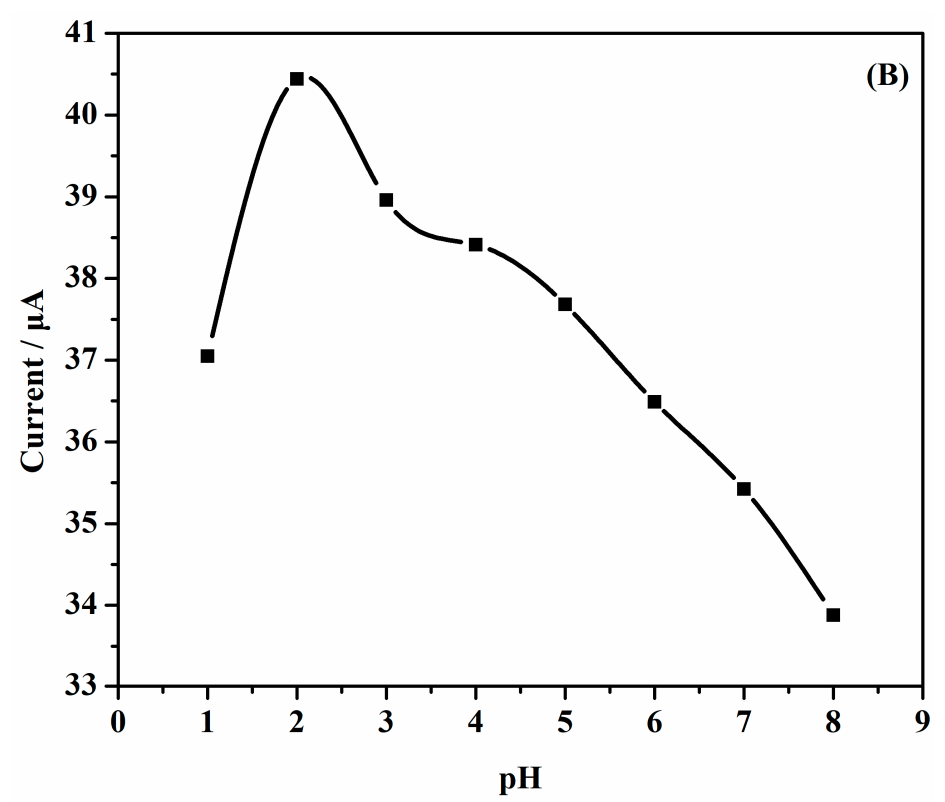

Figure 7. (A) CVs of a solution of $1.0 \times 10^{-3} \mathrm{~mol} \cdot \mathrm{L}^{-1} \mathrm{SAM}$ AuNPs/Gr/GCE at various buffered pHs: (a) 1.0; (b) 2.0; (c) 3.0; (d) 4.0; (e) 5.0; (f) 6.0; (g) 7.0; (h) 8.0; (B) Effects of pH and the oxidation peak current of $1.0 \times 10^{-3} \mathrm{~mol} \cdot \mathrm{L}^{-1} \mathrm{SAM}$.

\subsection{Effects of Different AuNPs/Gr Modification Volume}

As can be seen from Figure 8, when the modification volume was $2 \mu \mathrm{L}$, the oxidation peak current was the highest and the electrochemical response was the strongest. Therefore, $2 \mu \mathrm{L}$ was chosen as the best volume of modification.

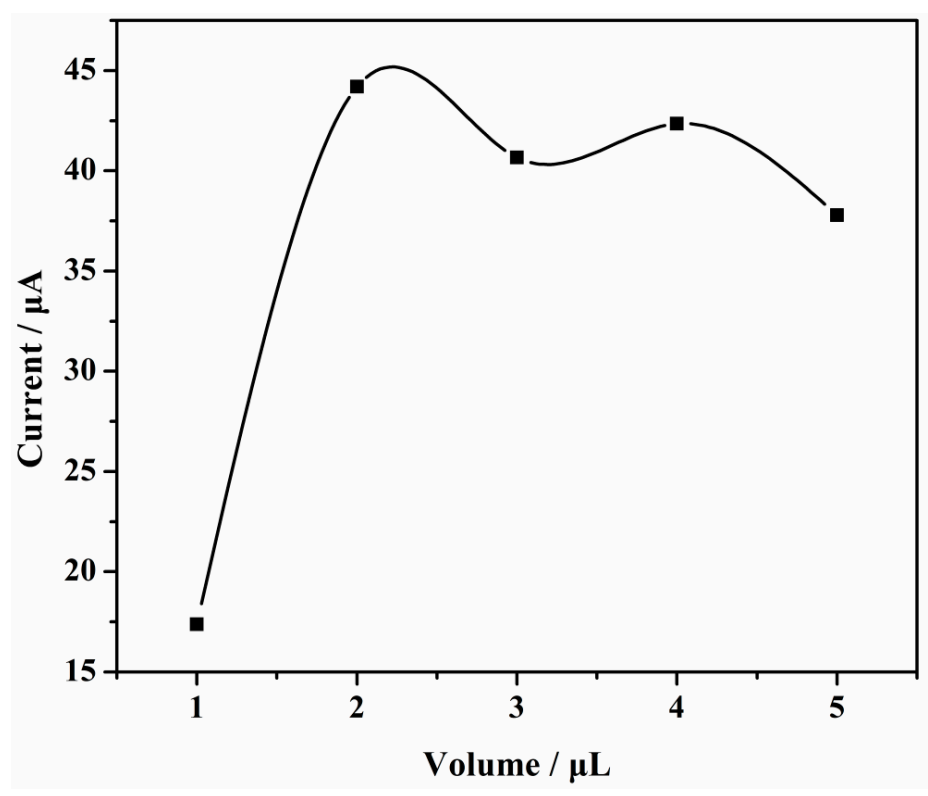

Figure 8. Relationship of the oxidation peak current versus volume of modification.

\subsection{Determination of $S A M$}

Under the optimal conditions, the standard curve was determined by using AuNPs/Gr/GCE to measure the oxidation peak current of a series of different concentrations of SAM solution. Based on the differential pulse voltammetry (DPV) method, as shown in Figure 9a, as the concentration of the 
SAM solution increased, the DPV current also increased. Figure $9 \mathrm{~b}$ shows a good linearity of the DPV current versus SAM concentrations in the range of $0.1-1000 \mu \mathrm{mol} \cdot \mathrm{L}^{-1}$. The linear regression equation was: $I(\mu \mathrm{A})=-9.837 \times 10^{-2}+16.39 \mathrm{c}\left(\mathrm{mmol} \cdot \mathrm{L}^{-1}\right)\left(\mathrm{R}^{2}=0.998\right)$. From the plot, the calculated limit of detection (LOD) was $0.011 \mu \mathrm{mol} \cdot \mathrm{L}^{-1}$ on the basis of the $3 \mathrm{SD} / n$ method, where 'SD' is the standard deviation of the blank solution and ' $n$ ' is the slope of the standard curve. The experimental result indicated that our proposed method possessed a wider dynamic range and a lower limit of detection relative to previous methods (Table 1 ).
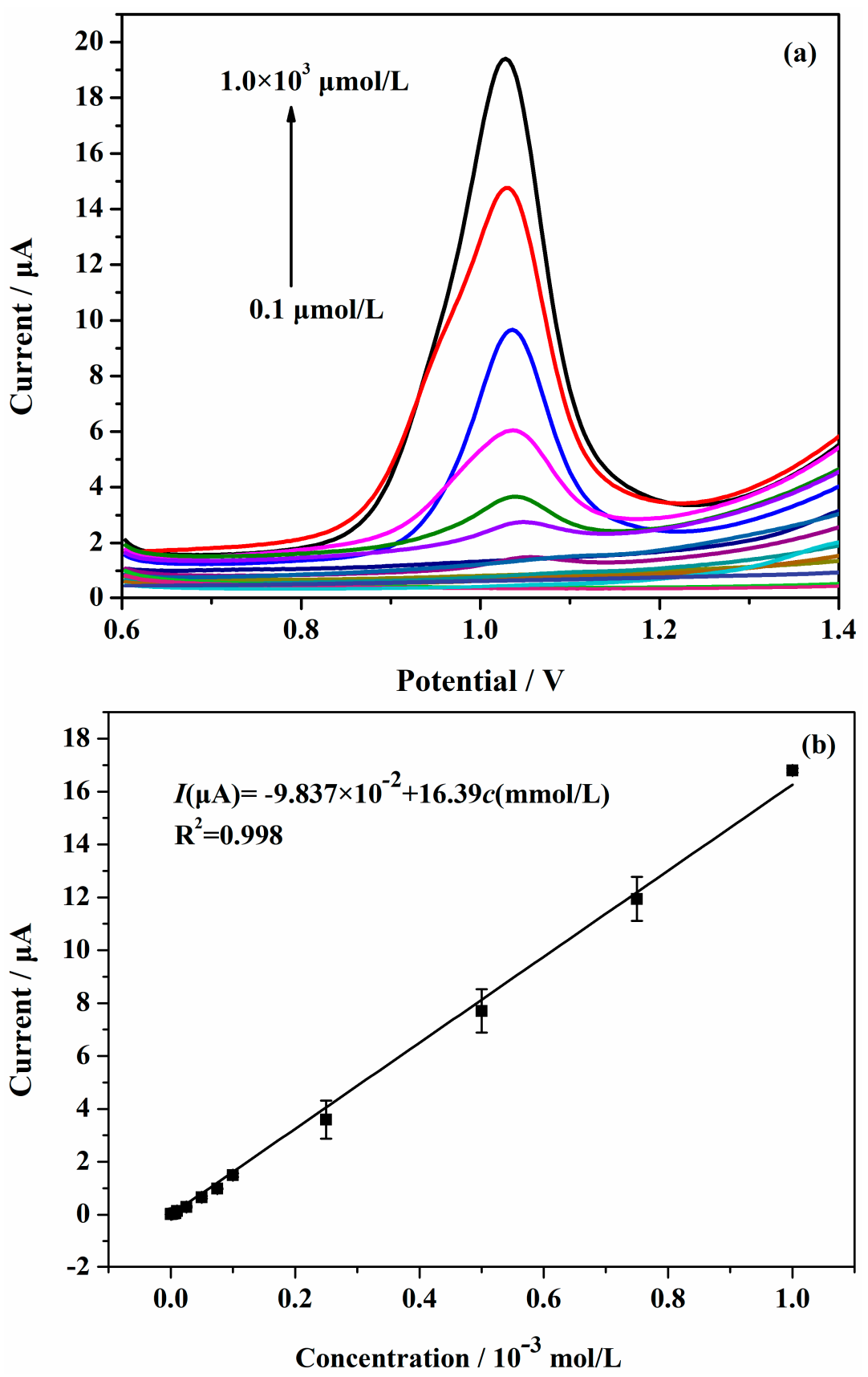

Figure 9. (a) Differential pulse voltammetry (DPV) measurements of different concentrations of SAM in $0.04 \mathrm{~mol} \cdot \mathrm{L}^{-1}$ Britton-Robinson (BR) buffer solution ( $\mathrm{pH}$ 2.0) using $2 \mu \mathrm{L}$ AuNPs/Gr/GCE; (b) The plots of linear relationship between SAM concentration and oxidation peak current: 0.1 to $1000 \mu \mathrm{mol} \cdot \mathrm{L}^{-1}$. The potential sweep rate was $100 \mathrm{mV} \cdot \mathrm{s}^{-1}$. (Amplitude: $0.05 \mathrm{~V}$, pulse width: $0.2 \mathrm{~s}$, sampling width: $0.0167 \mathrm{~s}$, pulse period: $0.5 \mathrm{~s})$. 
Table 1. Comparison of SAM determinations using the proposed and reference methods.

\begin{tabular}{ccccc}
\hline Method & Electrode & $\begin{array}{c}\text { Linear Range } \\
\left(\mu \mathbf{m o l} \cdot \mathbf{L}^{-\mathbf{1}}\right)\end{array}$ & $\begin{array}{c}\text { Limit of } \\
\text { Detection }\end{array}$ & Reference \\
\hline$i-t$ & $\mathrm{Fe}_{3} \mathrm{O}_{4} / \mathrm{Gr} / \mathrm{GCE}$ & $0.5-110$ & 0.05 & {$[19]$} \\
$\mathrm{CV}$ & Carboxyl/DMF/MWCNTs/GCE $^{\mathrm{a}}$ & $1.0-100$ & 0.5 & {$[20]$} \\
$\mathrm{FL}^{\mathrm{b}}$ & ${\mathrm{MIPs} / \mathrm{QDs} @ \mathrm{SiO}_{2}{ }^{\mathrm{c}}}_{\mathrm{DPV}}^{\mathrm{Py} / \mathrm{MIP} \mathrm{PGE}{ }^{\mathrm{d}}}$ & $2.0-30$ & 0.17 & {$[21]$} \\
$\mathrm{DPV}$ & $\mathrm{Gr} / \mathrm{AuNPs} / \mathrm{GCE}$ & $0.05-1.1,1.1-48$ & 0.02 & {$[32]$} \\
\hline
\end{tabular}

${ }^{a}$ Carboxyl/N,N-dimethylformamide/Multi-walled carbon/GCE; ${ }^{b}$ Fluorescence; ${ }^{c}$ Molecularly imprinted polymers/Quantum dots@SiO ${ }_{2} ;{ }^{\mathrm{d}}$ Pyrrole/Molecularly imprinted polymer pencil graphite electrode.

\subsection{Interferences Study}

To evaluate the effects of interfering substances on the detection of SAM, CV was performed in $1.0 \times 10^{-3} \mathrm{~mol} \cdot \mathrm{L}^{-1} \mathrm{SAM}$ solution containing interference species. Specifically, 200-fold of glucose and sucrose, and 300-fold of $\mathrm{NaCl}, \mathrm{KCl}, \mathrm{CaCl}_{2}$, and $\mathrm{MgSO}_{4}$ were added into the $\mathrm{SAM}$ solutions, respectively. It was found that 300 -fold of $\mathrm{NaCl}, \mathrm{KCl}, \mathrm{CaCl}_{2}, \mathrm{MgSO}_{4}$ had little interference effect on the detection of SAM, but 200-fold of glucose and sucrose had a great impact. As shown in Table 2, only 50-fold of sucrose and glucose led to approximately $\pm 5 \%$ relative error in the assay. Therefore, in the real sample testing, the effects of a high concentration of glucose and sucrose needed to be considered.

Table 2. Effects of interfering substances on the determination of SAM solution of $1 \times 10^{-3} \mathrm{~mol} \cdot \mathrm{L}^{-1}$ by AuNPs/Gr/GCE.

\begin{tabular}{ccc}
\hline Solution $\left(\mathbf{m o l} \cdot \mathbf{L}^{-\mathbf{1}}\right)$ & Current $(\boldsymbol{\mu A})$ & Rate of Change $(\mathbf{\%})$ \\
\hline $1.0 \times 10^{-3} \mathrm{SAM}$ & 26.18 & \multirow{2}{*}{3.44} \\
After addition of 50 -fold glucose & 25.38 & \multirow{2}{*}{3.00} \\
\hline $1.0 \times 10^{-3} \mathrm{SAM}$ & 22.28 & \multirow{2}{*}{2.60} \\
After addition of 50 -fold sucrose & 22.95 & \multirow{2}{*}{4.55} \\
\hline $1.0 \times 10^{-3} \mathrm{SAM}$ & 27.69 & \multirow{2}{*}{3.55} \\
After addition of 300 -fold $\mathrm{NaCl}$ & 28.41 & \\
\hline $1.0 \times 10^{-3} \mathrm{SAM}$ & 29.44 & \multirow{2}{*}{4.56} \\
After addition of 300 -fold $\mathrm{KCl}$ & 30.78 & \\
\hline $1.0 \times 10^{-3} \mathrm{SAM}$ & 28.48 & 29.49 \\
\hline After addition of 300 -fold $\mathrm{CaCl}_{2}$ & 28.46 & \\
\hline $1.0 \times 10^{-3} \mathrm{SAM}$ & 29.76 & \\
\hline
\end{tabular}

\subsection{Repeatability and Stability}

To evaluate the repeatability and stability, the corresponding experiments were studied. Under optimized conditions, SAM of $1.0 \times 10^{-3} \mathrm{~mol} \cdot \mathrm{L}^{-1}$ was continuously scanned 12 times. In this work, the change of oxidation peak current that occurred the first three times was small, but afterwards it changed obviously. The reason for this may be the surface passivation of AuNPs/Gr/GCE under acidic conditions, which hindered the electron transfer to the surface of AuNPs/Gr/GCE. The AuNPs/Gr/GCEs were observed for 0-15 h, respectively. The peak current of newly prepared AuNPs/Gr/GCE was $32.23 \mu \mathrm{A}$. After $15 \mathrm{~h}$, the peak current was $29.01 \mu \mathrm{A}$ with a reduction of $9.71 \%$ and the oxidation peak potential was almost unchanged. Therefore, AuNPs/Gr/GCE had high electrocatalytic activity and good stability. 


\subsection{Application of Sensor in a Real Sample}

To prove the feasibility of the AuNPs/Gr/GCE in real sample, the calibration experiment was studied. Pork extract was selected as the sample, and the content and recovery of SAM in the diluted sample solutions were determined via the standard adding method. The established standard curve equation in the above experiment was used to calculate the content of SAM. The results are shown in Table 3. In the three parallel experiments the average recoveries ranged from $91.22 \%$ to $96.67 \%$, thus indicating that the sensor could successfully detect SAM in a real sample.

Table 3. Recovery experimental results of the determination of SAM in a real sample.

\begin{tabular}{|c|c|c|c|c|}
\hline Sample & Added $\left(10^{-5} \mathrm{~mol} \cdot \mathrm{L}^{-1}\right)$ & Found $\left(10^{-5} \mathrm{~mol} \cdot \mathrm{L}^{-1}\right)$ & Recovery (\%) & Average Recovery (\%) \\
\hline \multirow{9}{*}{ SAM } & & 2.69 & 89.67 & \multirow{3}{*}{91.22} \\
\hline & 3.0 & 2.74 & 91.33 & \\
\hline & & 2.78 & 92.67 & \\
\hline & \multirow{3}{*}{6.0} & 5.43 & 90.50 & \multirow{3}{*}{96.67} \\
\hline & & 5.85 & 97.50 & \\
\hline & & 6.12 & 102.00 & \\
\hline & \multirow{3}{*}{9.0} & 7.73 & 85.89 & \multirow{3}{*}{94.67} \\
\hline & & 8.76 & 97.33 & \\
\hline & & 9.07 & 100.78 & \\
\hline
\end{tabular}

\section{Conclusions}

A simple and feasible electrochemical sensor based on AuNPs/Gr nanocomposites was provided for detecting SAM. The AuNPs/Gr nanocomposites have a better performance compared with pure Gr for the detection of SAM owing to their high conductivity and large surface area. Furthermore, the prepared AuNPs/Gr/GCE possessed a certain stability, good selectivity, and acceptable recovery abilities. Based on the abovementioned characteristics, it could be promising in the practical application of detecting in a real sample.

Acknowledgments: This work was supported by the National Natural Science Foundation of China (Grant No. 61301037), Henan Science and Technology Cooperation Project (Grant No. 172106000014), Foundation of Henan Educational Committee (Grant No. 13A550194), Cultivation Plan for Young Core Teachers in Universities of Henan Province (No. 2017GGJS072), Fundamental Research Funds for the Henan Provincial Colleges and Universities (Grant No. 2014YWQQ05), and Youth Backbone Teacher Training Program of Henan University of Technology.

Author Contributions: Bao-Shan He and Xiao-Hai Yan conceived and designed the experiments; Xiao-Hai Yan performed the experiments; all authors analyzed the data; Bao-Shan He and Xiao-Hai Yan wrote the paper; all authors discussed the results and commented on the paper.

Conflicts of Interest: The authors declare no conflict of interest.

\section{References}

1. Khezeli, T.; Daneshfar, A.; Sahraei, R. Emulsification liquid-liquid microextraction based on deep eutectic solvent: An extraction method for the determination of benzene, toluene, ethylbenzene and seven polycyclic aromatic hydrocarbons from water samples. J. Chromatogr. A 2015, 1425, 25-33. [CrossRef] [PubMed]

2. Xia, L.; Liu, L.; Lv, X.; Qu, F.; You, J. Towards the determination of sulfonamides in meat samples: A magnetic and mesoporous metal-organic framework as an efficient sorbent for magnetic solid phase extraction combined with high-performance liquid chromatography. J. Chromatogr. A 2017, 1500, 24-31. [CrossRef] [PubMed]

3. Lahcen, A.A.; Amine, A. Mini-Review: Recent Advances in Electrochemical Determination of Sulfonamides. Anal. Lett. 2017, 51, 424-441. [CrossRef]

4. Chatzimitakos, T.; Samanidou, V.; Stalikas, C.D. Graphene-functionalized melamine sponges for microextraction of sulfonamides from food and environmental samples. J. Chromatogr. A 2017, 1522, 1-8. [CrossRef] [PubMed] 
5. Errayess, S.A.; Lahcen, A.A.; Idrissi, L.; Marcoaldi, C.; Chiavarini, S.; Amine, A. A sensitive method for the determination of Sulfonamides in seawater samples by Solid Phase Extraction and UV-Visible spectrophotometry. Spectrochim. Acta A Mol. Biomol. Spectrosc. 2017, 181, 276-285. [CrossRef] [PubMed]

6. Xu, Y.; Zhao, Q.; Jiang, L.; Li, Z.; Chen, Y.; Ding, L. Selective determination of sulfonamides from environmental water based on magnetic surface molecularly imprinting technology. Environ. Sci. Pollut. Res. 2017, 24, 9174-9186. [CrossRef] [PubMed]

7. Yu, W.; Li, K.; Liu, Z.; Zhang, H.; Jin, X. Novelty aqueous two-phase extraction system based on ionic liquid for determination of sulfonamides in blood coupled with high-performance liquid chromatography. Microchem. J. 2017, 136, 263-269. [CrossRef]

8. Li, Z.; Li, Y.; Qi, M.; Zhong, S.; Wang, W.; Wang, A.J.; Chen, J. Graphene-Fe ${ }_{3} \mathrm{O}_{4}$ as a magnetic solid-phase extraction sorbent coupled to capillary electrophoresis for the determination of sulfonamides in milk. J. Sep. Sci. 2016, 39, 3818-3826. [CrossRef] [PubMed]

9. Fu, X.; Liang, H.; Xia, B.; Huang, C.; Ji, B.; Zhou, Y. Determination of Sulfonamides in Chicken Muscle by Pulsed Direct Current Electrospray Ionization Tandem Mass Spectrometry. J. Agric. Food Chem. 2017, 65, 8256-8263. [CrossRef] [PubMed]

10. Hyunhee, C.; Jungbin, L.; Yunhee, C.; Kwanggeun, L. Analysis of sulfonamide and quinolone antibiotic residues in Korean milk using microbial assays and high performance liquid chromatography. Food Chem. 2009, 113, 297-301.

11. Jiménez, V.; Adrian, J.; Guiteras, J.; Marco, M.P.; Companyó, R. Validation of an Enzyme-Linked Immunosorbent Assay for Detecting Sulfonamides in Feed Resources. J. Agric. Food Chem. 2010, 58, 7526-7531. [CrossRef] [PubMed]

12. Hu, G.; Sheng, W.; Zhang, Y.; Wang, J.; Wu, X.; Wang, S. Upconversion Nanoparticles and Monodispersed Magnetic Polystyrene Microsphere based Fluorescence Immunoassay for the Detection of Sulfaquinoxaline in Animal-derived Foods. J. Agric. Food Chem. 2016, 64, 3908-3915. [CrossRef] [PubMed]

13. Dmitrienko, S.G.; Kochuk, E.V.; Tolmacheva, V.V.; Apyari, V.V.; Zolotov, Y.A. Determination of the total content of some sulfonamides in milk using solid-phase extraction coupled with off-line derivatization and spectrophotometric detection. Food Chem. 2015, 188, 51-56. [CrossRef] [PubMed]

14. Niu, H.; Cai, Y.; Shi, Y.; Wei, F.; Liu, J.; Mou, S.; Jiang, G. Evaluation of carbon nanotubes as a solid-phase extraction adsorbent for the extraction of cephalosporins antibiotics, sulfonamides and phenolic compounds from aqueous solution. Anal. Chim. Acta 2007, 594, 81-92. [CrossRef] [PubMed]

15. Tarbin, J.A.; Clarke, P.; Shearer, G. Screening of sulphonamides in egg using gas chromatography-mass- selective detection and liquid chromatography-mass spectrometry. J. Chromatogr. B Biomed. Sci. Appl. 1999, 729, 127-138. [CrossRef]

16. Berardi, G.; Bogialli, S.; Curini, R.; Di Corcia, A.; Laganá, A. Evaluation of a Method for Assaying Sulfonamide Antimicrobial Residues in Cheese: Hot-Water Extraction and Liquid Chromatography-Tandem Mass Spectrometry. J. Agric. Food Chem. 2006, 54, 4537-4543. [CrossRef] [PubMed]

17. Sheridan, R.; Mirabile, J.; Hafler, K. Determination of six illegal antibiotics in chicken jerky dog treat. J. Agric. Food Chem. 2014, 62, 3690-3696. [CrossRef] [PubMed]

18. Tso, J.; Dutta, S.; Inamdar, S.; Aga, D.S. Simultaneous analysis of free and conjugated estrogens, sulfonamides, and tetracyclines in runoff water and soils using solid-phase extraction and liquid chromatography-tandem mass spectrometry. J. Agric. Food Chem. 2011, 59, 2213-2222. [CrossRef] [PubMed]

19. He, B. Electrochemical Determination of Sulfonamide Based on Glassy Carbon Electrode Modified by $\mathrm{Fe}_{3} \mathrm{O}_{4}$ /Functionalized Graphene. Int. J. Electrochem. Sci. 2017, 12, 3001-3011. [CrossRef]

20. He, B.; Chen, W. Carboxyl Multiwalled Carbon Nanotubes through Ultrasonic Dispersing in Dimethylfomamide Modified Electrode as a Sensitive Amperometric Sensor for Detection of Sulfonamide. Int. J. Electrochem. Sci. 2014, 10, 4335-4345.

21. Wei, X.; Xu, G.; Gong, C.; Qin, F.; Gong, X.; Li, C. Fabrication and evaluation of sulfanilamide-imprinted composite sensors by developing a custom-tailored strategy. Sens. Actuators B Chem. 2018, 255, 2697-2703. [CrossRef]

22. Wang, G.; Chen, L.; Zhu, Y.; He, X.; Xu, G.; Zhang, X. Development of an electrochemical sensor based on the catalysis of ferrocene actuated hemin/G-quadruplex enzyme for the detection of potassium ions. Biosens. Bioelectron. 2014, 61, 410-416. [CrossRef] [PubMed] 
23. Wang, J.H.; Wei, W.; Guo, Z.X.; Shi, M.; Guo, R.P. Decreased Cezanne expression is associated with the progression and poor prognosis in hepatocellular carcinoma. J. Trans. Med. 2015, 13, 41. [CrossRef] [PubMed]

24. Liu, J.; Wang, X.; Wang, T.; Li, D.; Xi, F.; Wang, J.; Wang, E. Functionalization of Monolithic and Porous Three-Dimensional Graphene by One-Step Chitosan Electrodeposition for Enzymatic Biosensor. ACS Appl. Mater. Interfaces 2014, 6, 19997-20002. [CrossRef] [PubMed]

25. Zhang, Z.; Luo, L.; Zhu, L.; Ding, Y.; Deng, D.; Wang, Z. Aptamer-linked biosensor for thrombin based on AuNPs/thionine-graphene nanocomposite. Analyst 2013, 138, 5365-5370. [CrossRef] [PubMed]

26. Taghdisi, S.M.; Danesh, N.M.; Lavaee, P.; Ramezani, M.; Abnous, K. An electrochemical aptasensor based on gold nanoparticles, thionine and hairpin structure of complementary strand of aptamer for ultrasensitive detection of lead. Sens. Actuators B Chem. 2016, 234, 462-469. [CrossRef]

27. Kangkamano, T.; Numnuam, A.; Limbut, W.; Kanatharana, P.; Thavarungkul, P. Chitosan Cryogel with Embedded Gold Nanoparticles Decorated Multiwalled Carbon Nanotubes Modified Electrode for Highly Sensitive Flow Based Non-Enzymatic Glucose Sensor. Sens. Actuators B Chem. 2017, 246, 854-863. [CrossRef]

28. He, B.S.; Du, G.A. A simple and sensitive electrochemical detection of furazolidone based on an Au nanoparticle functionalized graphene modified electrode. Anal. Methods 2017, 9, 4341-4348. [CrossRef]

29. Sun, M.; Davenport, D.; Liu, H.; Qu, J.; Elimelech, M.; Li, J. Highly efficient and sustainable non-precious-metal Fe-N-C electrocatalysts for the oxygen reduction reaction. J. Mater. Chem. A 2017, 6, 2527-2539. [CrossRef]

30. Shan, C.; Yang, H.; Han, D.; Zhang, Q.; Ivaska, A.; Niu, L. Electrochemical determination of NADH and ethanol based on ionic liquid-functionalized graphene. Biosens. Bioelectron. 2010, 25, 1504-1508. [CrossRef] [PubMed]

31. Beiranvand, Z.S.; Abbasi, A.R.; Dehdashtian, S.; Karimi, Z.; Azadbakht, A. Aptamer-based electrochemical biosensor by using Au-Pt nanoparticles, carbon nanotubes and acriflavine platform. Anal. Biochem. 2016, 518, 35-45. [CrossRef] [PubMed]

32. Tadi, K.K.; Motghare, R.V.; Ganesh, V. Electrochemical Detection of Sulfanilamide Using Pencil Graphite Electrode Based on Molecular Imprinting Technology. Electroanalysis 2015, 26, 2328-2336. [CrossRef]

(C) 2018 by the authors. Licensee MDPI, Basel, Switzerland. This article is an open access article distributed under the terms and conditions of the Creative Commons Attribution (CC BY) license (http:/ / creativecommons.org/licenses/by/4.0/). 